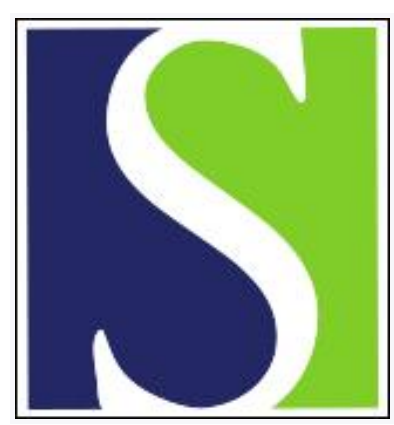

Scand J Work Environ Health 2011;37(3):237-243

https://doi.org/10.5271/sjweh.3152

Published online: 17 Feb 2011, Issue date: May 2011

Lens opacities among physicians occupationally exposed to ionizing radiation - a pilot study in Finland

by Mrena S, Kivelä T, Kurttio P, Auvinen A

Affiliation: School of Public Health, Fl-33014 University of Tampere, Finland. anssi.auvinen@uta.fi

Key terms: cataract; crystalline; exposure; Finland; Finland; ionizing radiation; lens; lens opacity; occupational; physician; pilot study; radiation effect; radiation protection; radiology

This article in PubMed: www.ncbi.nlm.nih.gov/pubmed/21340441 


\title{
Lens opacities among physicians occupationally exposed to ionizing radiation - a pilot study in Finland
}

\author{
by Samy Mrena, MD, PhD, ${ }^{1}$ Tero Kivelä, MD, PhD, ${ }^{1}$ Päivi Kurttio, PhD, ${ }^{2}$ Anssi Auvinen, MD, PhD 2,3
}

\begin{abstract}
Mrena S, Kivelä T, Kurttio P, Auvinen A. Lens opacities among physicians occupationally exposed to ionizing radiation- a pilot study in Finland. Scand J Work Environ Health. 2011;37(3):237-243. doi:10.5271/sjweh.3152.

Objectives The aim of this study was to estimate the prevalence of lens opacities among physicians occupationally exposed to radiation overall and by occupational factors and to assess the feasibility of a large-scale study for risk assessment.
\end{abstract}

Methods Based on a nationwide registry of 1312 physicians, mostly radiologists with occupational exposure to ionizing radiation, 120 subjects were invited to participate, of which 59 (49\%) consented. The inclusion criteria included (i) age 45-70 years, (ii) cumulative recorded radiation dose $>10 \mathrm{mSv}$, and (iii) duration of work with dose monitoring $>15$ years. The participants completed a questionnaire regarding occupational history and other risk factors for lens opacities. A full ophthalmological examination was performed. Lenticular changes were graded using the Lens Opacities Classification System, version II (LOCS II), and the Nidek EAS-1000 Scheimpflug slit-imaging videophotography system.

Results Lens opacities were detected in 42\% [95\% confidence interval (95\% CI) 29-55] of the 57 physicians without prior cataract surgery. Nuclear opacities were found in $14 \%$ (95\% CI 6-26), cortical in 7\% (95\% CI $2-17)$, and posterior subcapsular in 5\% (95\% CI 1-15) of the subjects. The prevalence of lens opacities increased with age, smoking, and cumulative recorded radiation dose. After controlling for age, gender, and smoking, the excess odds ratio for any lens opacity was 0.13 (95\% CI -0.02-0.28) per $10 \mathrm{mSv}$ of cumulative radiation dose.

Conclusions Our preliminary results show cortical and posterior subcapsular lens opacities among physicians exposed to occupational radiation, consistent with recent studies on low-dose radiation exposure. A full study with an unexposed reference group for risk estimation is warranted.

Key terms cataract; crystalline; exposure; occupational; radiology; radiation effects; radiation protection.

The incidence of lens opacities and cataract (opacity affecting sight) varies by age and diagnostic criteria used. Cataract formation is associated with trauma, smoking, nutrition, and intraocular inflammation, while ultraviolet radiation is a risk factor for cortical cataract (1-3). Hereditary factors play a role and medical risk factors include diabetes as well as corticosteroid, diuretic, and beta blocker use (4-9). Cataracts may occur more commonly among women (10).

Cataractogenesis associated with ionizing radiation is well known from experimental studies and has been demonstrated in humans by studies among survivors of the Hiroshima and Nagasaki atomic bombs (10-13). Cataract is a frequent complication of radiotherapy for intraocular melanoma (14-15). Radiation induces changes in the lens epithelium, causing typically posterior subcapsular cataracts (PSC). Yet other factors can also cause PSC and therefore it is not pathognomic to radiation. Furthermore, several studies have also shown increased frequency of cortical cataracts among radiation-exposed groups $(13,16)$. Radiation-related cataract has been regarded as a deterministic effect, which occurs only after high doses, with a threshold of approximately 1 Gy. However, this view has been challenged by recent studies, which have shown increased risk of lens opacities even after low-dose exposure (16-19).

Re-analyses of atomic bomb survivor data have demonstrated that the findings are compatible both with

1 Department of Ophthalmology, Helsinki University Central Hospital, Helsinki, Finland.

2 Research and Environmental Surveillance, Radiation and Nuclear Safety Authority (STUK), Helsinki, Finland.

3 School of Public Health, University of Tampere, Tampere, Finland.

Correspondence to: Anssi Auvinen, School of Public Health, FI-33014 University of Tampere, Finland. [E-mail: anssi.auvinen@uta.fi]. 
threshold (about 1.5 Sv) and linear models (10-13). In one study, children whose lens was exposed to 1 Gy during radiotherapy had a $50 \%$ increased risk of developing a posterior subcapsular opacity and a $35 \%$ higher risk for cortical lens opacities, compared with unexposed controls (16). Posterior subcapsular opacities were also more frequent among Ukrainian children affected by the fallout from the Chernobyl nuclear power plant accident (prevalence 1\%) than controls (17). More than $50 \%$ of Icelandic airline pilots exposed to cosmic radiation had some lens opacities while 7-8\% of them had PSC (18). Finally, screening of 59 participants of the annual meeting of the Society of Interventional Radiology revealed posterior subcapsular opacities in $8 \%$ of participants and smaller dot-like lens opacities in 37\% (20-21).

We conducted a pilot study (i) to determine whether the frequency of lens opacities among physicians occupationally exposed to ionizing radiation, especially those types previously associated with radiation (cortical and posterior subcapsular changes), is high enough to justify a full analytical study and (ii) to assess the relation of lens opacities to indicators of radiation exposure.

\section{Methods}

The population at risk was identified from the Finnish national occupational radiation exposure registry maintained by the Radiation and Nuclear Safety Authority (STUK), a governmental institution responsible for radiation protection in Finland. At the time of the study, STUK's registry covered a total of 1312 physicians monitored for radiation exposure.

Eligible subjects were physicians included in the occupational exposure registry aged $45-70$ years, with a history of dose monitoring $\geq 15$ years, and a recorded cumulative effective dose $>10 \mathrm{mSv}$. The effective dose is a whole-body dose weighted by a factor indicating the risk of health detriment. No separate dose estimates for the lens of the eye were available. The information for assessment of eligibility was obtained from the dose registry. For logistic reasons, the subjects had to be current residents of the Uusimaa region (including Helsinki) in Southern Finland, which is home to a quarter of the Finnish population. All 120 subjects who fulfilled these criteria were invited to participate.

The year of start and duration of dose monitoring, as well as the recorded cumulative dose, were obtained from the registry. The recorded doses are based on film dosimeters worn outside the lead apron at work, which therefore overestimate the effective dose by at least a factor of 10. A single detector can only give a crude indication of the workload and exposure opportunity given that the dose results mainly from scatter of the primary beam from the patient. The relation of the recorded dose to the exposure to the eye is complex and it is unclear if measurements above or below the lead apron are better indicators of ocular doses. Furthermore, the registry covers only doses exceeding the recording threshold, which was decreased over time from $3.0 \mathrm{mSv}$ to $0.1 \mathrm{mSv}$ in a three-month monitoring period (3.0 mSv in 1969-1974, $1.5 \mathrm{mSv}$ in $1975-1979,0.5 \mathrm{mSv}$ in $1980-1988,0.3 \mathrm{mSv}$ in 1989-1997, and finally $0.1 \mathrm{mSv}$ from 1998 onward). Recorded doses were not available before 1969 and earlier doses were missing. The frequency of missing dosimeter readings was very low $(<0.1 \%)$ for the period covered by the dose registry.

All 120 eligible subjects were contacted by mail and invited to participate in the study. The radiological society was contacted prior to the study and it informed its members in advance. The letter explained the purpose and procedures of the study and included also the study questionnaire for collection of information on medical and work history, use of radiation shielding, and smoking. The 59 subjects who gave their consent were asked to fill in the questionnaire. Based on questionnaire data and ophthalmological examinations, two subjects with prior cataract surgery were excluded from the study.

The study subjects underwent a comprehensive eye examination at the Department of Ophthalmology, Helsinki University Hospital after pupillary dilatation. The Lens Opacities Classification System, version II (LOCS II) was used to grade lens changes (22). LOCS II utilizes a set of standard slit-lamp and retro-illumination color transparencies for grading the different degrees of nuclear, cortical, and subcapsular cataract. The system has four grades for nuclear opalescence and color, five grades for cortical, and four for subcapsular opacities. If the two eyes differed in grade, the worse grade was recorded. In the analysis, cortical and posterior subcapsular (ie, non-nuclear) opacities were combined as these are the two types associated with radiation in earlier studies and a meaningful analysis of either type separately is not possible due to the small resulting number. The Nidek EAS-1000 Scheimpflug slit-imaging videophotography system (Nidek, Aichi, Japan) was used to objectively record the lens findings.

\section{Statistical analysis}

The $95 \%$ confidence intervals $(95 \% \mathrm{CI})$ for prevalences were calculated using the binomial distribution. Frequencies of categorical variables were compared using the chi-square test and the Fisher's exact test for small frequencies. Differences in mean age, cumulative dose, and duration of work career between subjects with and without lens opacities were evaluated with the nonparametric Kolmogorov-Smirnov test (due to the skewed distribution). SPSS 16.0 (SPSS Inc, Chicago, IL, USA) 
was used for descriptive statistics. STATA statistical software, version 10, (StataCorp, College Station, TX, USA) was used for logistic regression with presence versus absence of lens opacities as the binary response variable. The main results are based on any lens opacities (LOCS grade 1-2 nuclear, cortical and posterior subcapsular opacities), but a separate analysis was also conducted for cortical and posterior opacities combined (excluding nuclear opacities from the analysis).

The ethical committee of the Helsinki University Central Hospital approved the study protocol (tracking number 352/E9/06), and we followed the tenets of the Helsinki Declaration.

\section{Results}

Of the 59 radiation-exposed physicians, 2 ( 3 eyes) had been operated for cataract and were excluded from the analysis - hence the results are presented for 57 subjects.

The mean age at examination of the 57 remaining physicians ( 28 men and 29 women) was 58 years (median 60 , range $46-70$ years). The majority were radiologists (40, including 11 interventional radiologists). Additionally, 16 cardiologists and a surgeon were included. The mean duration of radiation work was 24 years (median 25, range 4-45 years). Eleven subjects (19\%) reported having used protective eyewear (lead glass spectacles), but only six (11\%) had used them regularly.

Of the 57 examined physicians, 33 (58\%) had no signs of cataract, whereas a lens opacity was found among 24 $(42 \%)$ subjects $(95 \%$ CI $29-56)$ when cortical traces $(9$ subjects without other opacity) were included. When cortical traces were excluded, the prevalence of LOCS II opacities was $26 \%$ (15 subjects) $(95 \%$ CI $16-40)$. All the opacities detected at ophthalmological examinations were minor. Nuclear opacities were the most common finding [8 (14\%) subjects (95\% CI 6-26), including nuclear colour changes observed in $6(11 \%)$ subjects $(95 \% \mathrm{CI}$ 4-22). Cortical opacities (grade 1-2 changes) were found in $4(7 \%)$ cases $(95 \%$ CI $2-17 \%)$, with $9(17 \%)$ additional subjects $(95 \%$ CI 7-28) showing cortical traces.

Posterior subcapsular opacities were found among 3 (5\%) subjects ( $95 \%$ CI \% 1-15). These included one subject with bilateral grade- 1 opacities and one with a unilateral grade- 2 opacity. The physicians with posterior subcapsular opacities were aged 67, 68, and 70 years, and had radiation work histories of 31-36 years with cumulative doses of 11,22 , and $24 \mathrm{mSv}$. One was a radiologist and the other two interventional radiologists. Furthermore, two subjects had minor dots that did not qualify as grade-1 changes. In addition, an interventional radiologist with a previously operated cataract in one eye had a posterior subcapsular opacity in the other.
The physicians with any lens opacities were older (mean age 64 versus 54 years among subjects without any lens changes, $\mathrm{P}<0.001$ ) and more commonly smokers than those without such eye changes (table 2). They also had had a longer career ( 30 versus 20 years, $\mathrm{P}<0.001)$ and a higher cumulative radiation dose $(84$ versus $42 \mathrm{mSv}, \mathrm{P}=0.02$ ).

All lens opacities combined, as well as cortical and posterior opacities combined (non-nuclear opacities) were associated with increasing age (table 2). Smoking was significantly associated with all lens opacities combined, but not with cortical and posterior lens changes. Prior medical conditions were not significantly associated with lens opacities. Starting radiation work prior to 1975 was associated with all types of lens changes, as well as non-nuclear opacities. Having been monitored for radiation dose for $\geq 20$ years was associated with all lens opacities combined.

Age and smoking status were associated with significantly increased prevalence of lens opacities in the logistic regression analysis even after mutual adjustment (table 3). After controlling for age, gender, and smoking, the excess odds ratio (OR) was $0.13(95 \% \mathrm{CI}$ $-0.02-0.28)$ per $10 \mathrm{mSv}$ of cumulative radiation dose for all opacities combined. Duration of radiation work was associated with the presence of any lens opacities in the bivariate analysis, but the association was no longer significant after adjusting for age.

When nuclear changes were excluded, the cumulative radiation dose was not associated with cortical and posterior opacities [excess OR (per $10 \mathrm{mSv}$ ) 0.04, (95\% CI -0.20-0.28)]. Interventional radiologists and cardiologists did not have a significantly higher risk of cortical and posterior lens changes compared with other specialists (mainly other radiologists).

Inclusion of the seven subjects with cortical traces and the two subjects with previously operated cataracts as cases did not substantially affect the findings regarding the relation of lens changes to occupational radiation dose (results not shown).

\section{Discussion}

Lens opacities were common among Finnish physicians exposed to ionizing radiation, but the majority of them were nuclear opacities (half of all alterations, prevalence $14 \%$ ), which generally are not thought to be related to ionizing radiation. Posterior subcapsular opacities, which classically are associated with ionizing radiation, were found in $5 \%$ of the participants ( 3 out of 57), which is likely to be an underestimate as two subjects had undergone cataract surgery (with unknown location of the opacity, though one of the operated subjects had a 
Table 1. Distribution of lens opacities according to the Lens Opacity Classification System (LOCS II) among 57 radiologists (in one or both of the 114 eyes, excluding two subjects with previously operated cataracts) a

\begin{tabular}{|c|c|c|c|c|c|c|c|}
\hline & \multicolumn{7}{|c|}{ LOCS II grade } \\
\hline & \multicolumn{2}{|c|}{0} & \multicolumn{2}{|c|}{1} & \multicolumn{2}{|c|}{2} & \multirow[t]{2}{*}{$\geq 3$} \\
\hline & $\mathrm{N}$ & $\%$ & $\mathrm{~N}$ & $\%$ & $\mathrm{~N}$ & $\%$ & \\
\hline Nuclear color & 51 & 89 & 6 & 11 & 0 & & 0 \\
\hline Nuclear opacity & 49 & 86 & 8 & 14 & 0 & & 0 \\
\hline Cortical opacity ${ }^{b}$ & 46 & 81 & 3 & 5 & 1 & 2 & 0 \\
\hline Posterior subcapsular opacity & 54 & 95 & 2 & 4 & 1 & 2 & 0 \\
\hline
\end{tabular}

a LOCS II grades different degrees of opacities (opaqueness) in nuclear (central part of the lens), cortical (outer layer of the lens) and posterior subcapsular cataracts (rear portion of the lens and underneath the lens capsule) by using standard images.

${ }^{b}$ In accordance with LOCS II, 7 subjects who had cortical traces are not shown on this row and the total number of subjects is thus 50 .

Table 2. Demographic, medical and occupational characteristics among subjects without lens changes, any opacities, and posterior or cortical opacities among 57 Finnish physicians occupationally exposed to ionizing radiation classified according to the Lens Opacity Classification System (LOCS II). Note that cortical and posterior changes are also included in "any opacities" as well as nuclear changes; only LOCS grade I-II changes shown.

\begin{tabular}{|c|c|c|c|c|c|c|c|c|}
\hline & \multicolumn{2}{|c|}{ No lens changes } & \multicolumn{2}{|c|}{ Any opacity } & \multirow[t]{2}{*}{ P-value } & \multicolumn{2}{|c|}{$\begin{array}{l}\text { Cortical or } \\
\text { posterior }\end{array}$} & \multirow[t]{2}{*}{ P-value } \\
\hline & $\%$ & $\mathrm{~N}=33$ & $\%$ & $\mathrm{~N}=24$ & & $\%$ & $\mathrm{~N}=7$ & \\
\hline \multicolumn{9}{|l|}{$\begin{array}{l}\text { Demographic, lifestyle and medical } \\
\text { factors }\end{array}$} \\
\hline Male gender & 42 & 14 & 58 & 14 & & 71 & 5 & \\
\hline Age & & & & & & & & $0.002^{a}$ \\
\hline $40-59$ years & 73 & 24 & 17 & 4 & & 0 & & \\
\hline $60-70$ years & 27 & 9 & 83 & 20 & $<0.001$ & 100 & 7 & \\
\hline History of diabetes & 3 & 1 & 8 & 2 & & 14 & 1 & \\
\hline History of ocular injury & 15 & 5 & 17 & 4 & & 0 & & \\
\hline Corticosteroid use ${ }^{b}$ & 9 & 3 & 8 & 2 & & 0 & & \\
\hline Family history of cataracts & 42 & 14 & 33 & 8 & & 57 & 4 & \\
\hline \multicolumn{9}{|l|}{ Smoking } \\
\hline Never smokers & 85 & 28 & 58 & 14 & & 71 & 5 & \\
\hline Ever smokers & 15 & 5 & 42 & 10 & 0.025 & 29 & 2 & \\
\hline \multicolumn{9}{|l|}{ Work-related factors } \\
\hline Daily radiation work & 33 & 11 & 58 & 14 & & 71 & 5 & \\
\hline Protective eyewear regularly c & 13 & 4 & 9 & 2 & & 0 & & \\
\hline Interventional radiology or cardiology & 39 & 14 & 54 & 13 & & 57 & 4 & \\
\hline Start of radiation work & & & & & & & & $0.001^{\mathrm{a}}$ \\
\hline 1975-2000 & 76 & 35 & 33 & 16 & & 0 & & \\
\hline $1962-1974$ & 24 & 8 & 67 & 8 & 0.001 & 100 & 7 & \\
\hline \multicolumn{9}{|l|}{ Duration of radiation work ${ }^{d}$} \\
\hline $5-20$ years & 45 & 15 & 17 & 4 & & 14 & 1 & \\
\hline $21-45$ years & 55 & 18 & 83 & 20 & 0.02 & 86 & 6 & \\
\hline \multicolumn{9}{|l|}{ Cumulative recorded radiation dose ${ }^{d}$} \\
\hline $10-30 \mathrm{mSv}$ & 64 & 21 & 37 & 9 & & 57 & 4 & \\
\hline 30-304 mSv & 36 & 12 & 63 & 15 & 0.04 & 43 & 3 & \\
\hline
\end{tabular}

a Fisher's exact test, two-sided.

b Includes systemic corticosteroids, eye drops, and strong ointments.

c Missing data for two subjects: one with and one without lens opacities.

${ }^{d}$ Missing data for one subject without lens opacities.

posterior lens opacity in the other eye at examination). Cortical opacities were found among 7\% subjects, but another $17 \%$ had cortical traces, and if these findings are included the proportion of subjects with cortical opacities is as high as $19 \%$, exceeding the number of nuclear findings. None of the subjects had a cataract that would require surgery.

We obtained some evidence that the lens opacities might be associated with the cumulative radiation dose. Overall, the exposure levels were well below those traditionally thought for cataract induction, in the entire study group (mean $60 \mathrm{mSv}$, maximum $300 \mathrm{mSv}$ ), as well as those with the posterior subcapsular (mean 19 $\mathrm{mSv}$ ) and cortical opacities (mean $65 \mathrm{mSv}$, maximum 72 $\mathrm{mSv}$ ). Also, the risk estimates obtained were substantially larger than those found in dose-response analyses among 
Table 3. Logistic regression analysis of any lens opacity as well as cortical and posterior opacity according to the Lens Opacity Classification System (LOCS II) by age, gender, smoking status, duration of radiation work, type of work intervention procedures versus other and cumulative recorded radiation dose. [0R=0dds ratio; $95 \% \mathrm{Cl}=95 \%$ confidence interval.]

\begin{tabular}{|c|c|c|c|c|}
\hline Risk factor & Crude OR & $95 \% \mathrm{Cl}$ & Adjusted $\mathrm{OR}{ }^{\text {a }}$ & $95 \% \mathrm{Cl}$ \\
\hline \multicolumn{5}{|l|}{ Any type of lens opacity } \\
\hline Age (excess per year) ${ }^{b}$ & 0.26 & $0.12-0.41$ & 0.29 & $0.13-0.48$ \\
\hline Gender (male versus female) ${ }^{c}$ & 1.90 & $0.65-5.51$ & 0.68 & $0.15-3.12$ \\
\hline Smoking (ever versus never) ${ }^{\mathrm{c}}$ & 4.00 & $1.14-14.0$ & 5.44 & $1.04-28.6$ \\
\hline Duration of radiation work (excess per year) b & 0.01 & $0.00-0.02$ & $0.01^{d}$ & $-0.08-0.10$ \\
\hline Interventional radiology $c, e$ & 2.36 & $0.77-7.28$ & $3.87 \mathrm{~d}$ & $0.82-18.3$ \\
\hline Cumulative dose (excess per $10 \mathrm{mSv}$ ) ${ }^{\mathrm{b}}$ & 0.11 & $0.00-0.23$ & $0.13^{f}$ & $-0.02-0.28$ \\
\hline \multicolumn{5}{|c|}{ Cortical or posterior opacity excluding nuclear opacities } \\
\hline Smoking (ever versus never) ${ }^{c}$ & 1.70 & $0.28-10.4$ & $1.33^{f}$ & $0.20-8.64$ \\
\hline Duration of radiation work (excess per year) ${ }^{b}$ & 0.15 & $0.02-0.30$ & 0.00 & $-0.20-0.25$ \\
\hline Interventional radiology $c, d$ & 1.61 & $0.32-8.12$ & $1.28 \mathrm{~g}$ & $0.08-19.38$ \\
\hline Cumulative dose (excess per $10 \mathrm{mSv})^{\mathrm{b}}$ & -0.02 & $-0.16-0.13$ & $0.04^{f}$ & $-0.20-0.28$ \\
\hline
\end{tabular}

adjusted for age (continuous), gender and smoking status (never versus ever).

${ }^{\mathrm{b}}$ Continuous variable.

${ }^{\circ}$ Categorical variable.

${ }^{\mathrm{d}}$ Adjusted for age (continuous), gender and smoking status (never versus ever).

e Including both interventional radiologists and cardiologists.

${ }^{\dagger}$ Adjusted for age (continuous), unaffected by further adjustment by sex and smoking status.

${ }^{9}$ Adjusted for age and sex, could not be adjusted for smoking due to empty cells no smoking cases among intervention radiologists.

atomic bomb survivors (with excess OR of $0.03-0.04$ per $10 \mathrm{mSv})(10-13)$. Our cumulative dose estimates may, however, be underestimated due to the fact that the records were not available for periods prior to 1969. However, recent studies have suggested increased cataract rates following environmental and occupational radiation exposures with similar dose levels (16-21).

Radiation exposure varies greatly between radiologists. Those who perform interventional procedures such as catheterizations may receive doses approaching the annual dose limits (currently, $20 \mathrm{mSv}$ averaged over 5 years or $50 \mathrm{mSv}$ in any single year), whereas others receive no measurable exposure during their entire career. For the eye, the dose limit has been set at $150 \mathrm{mSv}$ per year. We selected the study subjects among those with the highest recorded doses, long work history, and tasks with potential for radiation exposure. Yet detailed information on frequency of performing various procedures was not collected. Fluoroscopies were more common previously while frequency of intervention procedures has increased during the past two decades. Therefore, those with a long career may represent a different range of exposures in terms of geometries, which we could assess crudely by taking into account the duration. Nevertheless, those working with fluoroscopic intervention procedures (interventional radiologists and cardiologists) had a higher frequency of cortical and posterior opacities combined than the other physicians.

We had information on occupational radiation exposure based on personal dosimeters, but no organ-specific doses for the eye. The Finnish occupational dose registry is comprehensive, and missing dosimeter readings is very rare. The available cumulative recorded doses likely substantially overestimate organ doses for most organs, because the dosimeters were worn outside the lead apron. However, as eye shields were rarely used, the recorded doses may be more appropriate indicators of exposure to the lens than organs protected by the apron. The radiation dose is primarily due to scatter from the patients and is highly non-uniform (23). On the other hand, the dose to the eyes depends heavily on the amount of radiation delivered to the patient and the proximity of the physician to the $\mathrm{x}$-ray tube. The radiation dose to the eye of the radiologist has been estimated as $0.4 \mathrm{mSv}$ per procedure for coronary angiography and balloon angioplasty (24). The infrequent use of eye protection may reflect a prevailing perception that risk for cataract is minimal or irrelevant. In our study, only one in five exposed physicians used any eye protection at all and only one in ten used them regularly. This is, however, similar to an earlier study (25). We had no information on the proportion of theatres equipped with ceiling-mounted screens, which also decrease the exposure levels.

Age is the strongest determinant of cataract occurrence, though the effect appears stronger for nuclear opacities than the other types (26-27). Other risk factors for both cortical and PSC include diabetes and steroid use, while smoking increases the risks of nuclear and PSC (28). The risk of cortical cataract is also related to ultraviolet radiation (29). We collected information on these factors and all analyses were adjusted for age, with additional adjustment for gender and smoking where necessary (if there was indication of confounding). Residual confounding, however, is always an issue, when assessment of exposure history to potential confounding factors in imperfect. 
We used the LOCS II classification, which has also been employed in previous studies to improve comparability. Minor changes such as dots, traces, or sheens (grade 0 in LOCS II) were not included in the analyses, as their importance is unclear.

An objective of this study was to evaluate the feasibility of undertaking a population-based epidemiological study of the effect of radiation work on risk of cataract. As the previous paradigm of cataracts occurring only after high doses has recently been challenged, there is great deal of interest in assessing the risk for cataract development related to occupational radiation exposure. The current pilot is the first step toward risk assessment, as it tested procedures for identifying and recruiting physicians and conducting ophthalmological examinations. Yet, it is limited by the small size and lack of an unexposed reference group.

Few previous studies have evaluated occurrence of lens opacities among medical personnel. Case reports indicate lens injuries following exposures substantially exceeding the dose limits (30). A recent study, without dosimetric information, showed a significantly increased risk among 35705 radiologic technologists (31). Similarly an Italian study showed increased prevalence among radiologists and radiological technicians compared with unexposed medical workers (32).

Our study focused on radiologists, and the findings were consistent with previous results, albeit inconclusive. Radiologists with any signs of cataract had a longer history of radiation work and a larger cumulative radiation dose than those not affected. Yet, risk of cataracts is strongly age-dependent, and also cumulative dose and career length increase with age. After adjustment for age, gender, and smoking the effect of dose was of borderline significance, and duration of radiation work was no longer significant.

The study indicates the feasibility and justification of a more comprehensive study on radiologists and cardiologists to assess the effect of radiation on the lens of the eye. A larger multi-centre study is warranted.

\section{Acknowledgements}

The study was supported by the Finnish Work Environment Fund. Samy Mrena also received support from the Mary and Georg C Ehrnrooth Foundation. We wish to acknowledge the technical assistance of Ms Maarit Halla-Seppälä, registered nurse at Helsinki University Hospital and Ms Anne Kreula from STUK.

\section{References}

1. Hodge WG, Whitcher JP, Satariano W. Risk factors for agerelated cataracts. Epidemiol Rev. 1995;17:336-346

2. Taylor HR, West SK, Rosenthal FS, Munoz B, Newland HS, Abbey H, Emmett EA. Effect of ultraviolet radiation on cataract formation. N Engl J Med. 1988;319:1429-33. doi:10.1056/NEJM198812013192201.

3. Delcourt C, Carirere I, Ponton-Sanchez A, Lacroux A, Cavacho MJ, Papoz L. Light exposure and the risk of cortical, nuclear, and posterior subcapsular cataracts: the Pathologies Oculaires Liees a l'Age (POLA) study. Arch Ophthalmol. 2000;118:385-92.

4. West S, Munoz B, Emmett EA, Taylor HR. Cigarette smoking and risk of nuclear cataracts. Arch Ophthalmol. 1989;107:1166-9.

5. Klein BE, Klein RE, Lee KE. Incident cataract after a fiveyear interval and lifestyle factors: the Beaver Dam eye study. Ophthalmic Epidemiol. 1999;6:247-55. doi:10.1076/ opep.6.4.247.4190.

6. Italian-American Cataract Study Group. Risk factors for agerelated cortical, nuclear and posterior subcapsular cataracts. Am J Epidemiol. 1991;133:541-53.

7. Leske MC, Chylack LT, Wu SY. The Lens Opacities CaseControl Study. Risk factors for cataract. Arch Ophthalmol. 1991;109:244-51.

8. Age-Related Eye-Diseases Study Group. Risk factors associated with age-related nuclear and cortical cataract: a case-control study in the Age-Related Eye Disease Study. Ophthalmology. 2001;108:1400-8. doi:10.1016/S01616420(01)00626-1.

9. Leske MC, Wu SY, Connell AM, Hyman L, Schachat AP. Lens opacities, demographic factors and nutritional supplements in the Barbados Eye Study. Int J Epidemiol. 1997;26:1314-22. doi:10.1093/ije/26.6.1314.

10. Otake M, Finch SC, Choshi K, Takaku I, Mishima H, Takase T. Radiation-related ophthalmological changes and aging among Hiroshima and Nagasaki A-bomb survivors: a re-analysis. Radiat Res. 1992;131:315-24. doi:10.2307/3578422.

11. Otake M, Neriishi K, Schull WJ. Cataract in atomic bomb survivors based on a threshold model and the occurrence of severe epilation. Radiat Res. 1996;146:339-48. doi: $10.2307 / 3579466$.

12. Minamoto A, Taniguchi H, Yoshitani N, Mukai S, Yokoyama $\mathrm{T}$, Kumagami T, et al. Cataract in atomic bomb survivors. Int J Radiat Biol. 2004;80:339-45. doi:10.1080/09553000410001 680332 .

13. Nakashima E, Neriishi K, Minamoto A. A reanalysis of atomicbomb cataract data, 2000-2002. Health Phys. 2006;90:154-60. doi:10.1097/01.HP.0000175442.03596.63.

14. Collaborative Ocular Melanoma Stydy Group. Incidence of cataract and outcomes after cataract surgery in the first five years after iodine-125 brachytherapy. Ophthalmology. 2007;114:1363-71. doi:10.1016/j.ophtha.2006.10.039. 
15. Finger PT, Chin KJ, Yu G-P, Patel NS. Risk factors for cataract after palladium-103 ophthalmic plaque radiation therapy. Int $\mathrm{J}$ Radiat Oncol Biol Phys. 2010 Jul 7. [Epub ahead of print].

16. Hall P, Granath F, Lundell M, Olsson K, Holm LE. Lenticular opacities in individuals exposed to ionizing radiation in infancy. Radiat Res. 1999;152:190-5. doi:10.2307/3580093.

17. Day R, Gorin MB, Eller AW. Prevalence of lens changes in Ukrainian children residing around Chernobyl. Health Phys. 1995;68:632-42. doi:10.1097/00004032-199505000-00002.

18. Rafnsson V, Olafsdottir E, Hrafnkelsson J, Sasaki H, Arnarsson A, Jonasson F. Cosmic radiation increases the risk of nuclear cataract in airline pilots: a population-based case-control study. Arch Ophthalmol. 2005;123:1102-5. doi:10.1001/ archopht.123.8.1102.

19. Chen WL, Hwang JS, Hu TH, Chen MS, Chang WP. Lenticular opacities in populations exposed to chronic low-dose-rate gamma radiation from radiocontaminated buildings in Taiwan. Radiat Res. 2001;156:71-77. doi:10.1667/00337587(2001)156[0071:LOIPET]2.0.CO;2.

20. Haskal Z, Junk A, Machan L, Worgul B, editors. Cataract in Interventional Radiology: An Occupational Hazard? Proceedings of RSNA 2004. [cited 15 July 2010] Available from: http://rsna2004.rsna.org/rsna2004/V2004/conference/ event_display.cfm?id=66601\&em_id $=4417746$

21. Kaiser CP. Report from SIR: Cataracts present greater threat to IRs than previously thought. Diagnostic Imaging Online, March 28, 2004. [cited 15 July 2010 ] Available from: http:// www.diagnosticimaging.com/dinews/2004032801.shtml.

22. Chylack LT Jr, Leske MC, McCarthy D, Khu P, Kashiwagi T, Sperduto R. Lens opacities classification system II (LOCS II). Arch Ophthalmol. 1989;107:991-7.

23. Martin CJ. A review of radiology staff doses and dose monitoring requirements. Radiat Prot Dosim. 2009;136:14057. doi: $10.1093 / \mathrm{rpd} / \mathrm{ncp} 168$.
24. Niklason LT, Marx MV, Chan HP. Interventional radiologists: occupational radiation doses and risks. Radiology. 1993;187:729-33.

25. Karppinen J, Parviainen T, Servomaa A, Komppa T. Radiation risk and exposure of radiologists and patients during coronary angiography and PTCA. Radiat Prot Dosim. 1995;57:481-5.

26. McCarty CA, Mukesh BN, Dimitrov PN, Taylor HR. Incidence and progression of cataract in the Melbourne Visual Impairment Project. Am J Ophthalmol. 2003;136:10-7. doi:10.1016/S0002-9394(02)01844-5.

27. Varma R, Richter GM, Torres M, Foong AW, Choudhury F, Azen SP. Four-year incidence and progression of lens opacities: the Los Angeles Latino Eye Study. Am J Ophthalmol. 2010;149:728-34. doi:10.1016/j.ajo.2009.11.012

28. McCarty CA, Taylor HA. A review of the epidemiological evidence linking ultraviolet radiation and cataract. Dev Ophthalmol. 2002;35:21-31. doi:10.1159/000060807.

29. Robman L, Taylor H. External factors in develoment of cataract. Eye. 2005;19:1074-82. doi:10.1038/sj.eye.6701964.

30. Vano E, Gonzalez L, Beneytez F, Moreno F. Lens injuries induced by occupational exposure in non-optimized interventional radiology laboratories. Br J Radiol. 1998;71:728-33.

31. Chodik G, Bekiroglu N, Hauptmann M, Alexander BH, Freedman DM, Doody MM, et al. Risk of cataract after exposure to low doses of ionizing radiation: a 20-year prospective cohort study among US radiologic technologists. Am J Epidemiol. 2008;168:620-31. doi:10.1093/aje/kwn171.

32. Milacic S. Risk of occupational radiation-induced cataract in medical workers. Med Lav. 2009;100:178-86.

Received for publication: 14 June 2010 